Article

\title{
Carbon Footprint of Packaging Films Made from LDPE, PLA, and PLA/PBAT Blends in South Korea
}

\author{
Bulim Choi, Seungwoo Yoo and Su-il Park * \\ Department of Packaging, Yonsei University, Wonju 26493, Korea; bulimchoi@gmail.com (B.C.); \\ seungwooyoo@naver.com (S.Y.) \\ * Correspondence: parks@yonsei.ac.kr; Tel.: +82-33-760-2370
}

Received: 31 May 2018; Accepted: 4 July 2018; Published: 8 July 2018

\begin{abstract}
Bio-plastics such as polylactic acid (PLA) have been investigated as a sustainable alternative to petroleum-based plastics. In this study, the carbon footprint of packaging films made from LDPE, PLA, and PLA/PBAT blends was measured with three different waste scenarios based on the database of South Korea using life cycle assessment (LCA). The LCA followed ISO standards, and was a cradle-to-grave analysis. The functional unit was defined as 400,000 pieces of a film of $300 \times 250 \mathrm{~mm}$ with thickness of $0.06 \mathrm{~mm}$ for packaging bag manufacturing. The waste treatments considered were incineration, landfill, and recycling applied with the present conditions of South Korea. Under the present analysis conditions, the PLA film with landfill was the most effective for reducing carbon emission. The PLA/PBAT with incineration was the worst case among the packaging films tested. Incineration was the worst choice of waste treatment in terms of carbon dioxide emissions. Generally, landfill may not be the best option in terms of sustainability but landfill was a better option for waste treatment than incineration. In addition, before bio-plastics are blended with other material, the blending material should first be evaluated for its environmental impact. The blended bio-plastics with PLA, such as PLA/PBAT, can be more inimical to the environment in terms of carbon dioxide emissions than existing materials, such as LDPE.
\end{abstract}

Keywords: carbon footprint; life cycle assessment (LCA); packaging film; low-density polyethylene (LDPE); polylactic acid (PLA); polybutylene adipate terephthalate (PBAT)

\section{Introduction}

Bio-plastics have been regarded as a sustainable alternatives to petroleum-based plastics [1-3]. In particular, polylactic acid (PLA) is noted as the most promising material in the bio-plastic sector. Since PLA has properties comparable to those of polystyrene (PS) and polyethylene terephthalate (PET), it can replace these petroleum-based plastics for a wide range of applications [4,5]. In the global market of bio-plastics, the biodegradable polymers market is expected to grow to 5324.4 million dollars by 2021 [6]. In the case of PLA, 43.1\% of the market share came in 2016 [6].

Despite packaging films now gaining popularity and economic growth [7], PLA has limitations for use as a packaging film owing to its poor performance of mechanical and physical properties. Accordingly, various attempts have been made to improve the properties of PLA through blending with other bio-plastics [8-13].

Carbon is one of the fundamental elements for the composition of plastics and fuels [14]. The sustainability of managing carbon has been an issue for the past few decades due to global warming and climate change. There have been several studies about greenhouse gas (GHG) emissions in the packaging sector $[15,16]$. Various studies have assessed and compared PLA (or multilayer films with PLA) and petroleum-based polymers using the LCA method [17,18]. 
In addition, there have been various carbon footprint studies in terms of global warming potential (GWP) using LCA concerning the comparison of biopolymers and petroleum-based polymers (see Table 1). LCA studies showed that bio-based containers and films are a better alternative than petroleum based plastics regarding the environmental impact. A garbage bag of PBAT/starch blends had the lowest environmental impact in the climate change category in the cradle-to-gate approach among three materials: Bio-PE, PBAT/starch blends, and PE [2]. In another previous study that considers energy recovery in the end-of-life perspective, PLA film was best for environmental impact in the climate change categories among four materials: PLA/TPS/PLS, PLA, PET, and PP [4]. Additionally, the biocomposite film based on PLA, wood fiber, and thermoplastic starch (TPS) was more environmentally friendly than PP film in the global warming categories in the cradle-to-gate approach [1].

Some findings show that GHG emission results of PLA can be changed depending on kind of blended materials or system boundary. For example, the PLA clamshell container had a lower carbon dioxide emission than PET and a higher than PS materials when the cradle-to-grave process (including energy recovery and the energy production) was considered in the system boundary [8]. Similarly, in the cradle-to-grave-LCA study of the comparison between a PLA and polystyrene (PS) tray, the PLA-based tray (PLA and PLA/starch) had a higher environmental impact than the PS tray in both the climate change and the global warming categories [19]. In addition, the biocomposite film based on pectin jelly-corn starch caused slightly higher GWP value than the LDPE film [7]. Another LCA study dealt with bio-plastics such as polyhydroxyalkanoate (PHA), and gave similar results to that of PLA [20]. However, there was a study suggested that a PLA based box production could be more environmentally friendly than a PS box production when suitable waste treatment is applied [21].

This study aims to evaluate and compare GWP value $\left(\mathrm{CO}_{2}\right.$ eq.) of packaging films made from LDPE, PLA, and PLA/PBAT blends focusing on waste treatment scenarios with the cradle-to-grave approach in South Korea. Based on the results of the LCA, the conclusions, implications, and limitations of this study were discussed.

Table 1. Previous studies for the comparison of GHG emissions of biopolymers and petroleum-based polymers.

\begin{tabular}{|c|c|}
\hline Products & Comments \\
\hline $\begin{array}{l}\text { Bio-PE, PBAT/starch garbage } \\
\text { bag vs. PE garbage bag [2] }\end{array}$ & $\begin{array}{l}\text { Materials data obtained from Ecoinvent database and literature review. } \\
\text { This study considered waste scenario that is landfilling, landfilling with energy recovery, } \\
\text { incineration with energy recovery and composting, and composed of six types of waste } \\
\text { scenario. The data was collected from experiments and calculations. } \\
\text { Cradle-to-grave (raw material extraction, bag manufacture, transportation, and end of life) } \\
\text { PBAT/starch }<\text { Bio-PE }<\text { PE }\left(\mathbf{C O}_{2} \text { eq.) }\right.\end{array}$ \\
\hline $\begin{array}{l}\text { PLA/TPS/PLS(ML), PLA film } \\
\text { vs. PET, PP film [4] }\end{array}$ & $\begin{array}{l}\text { Most data used were from Ecoinvent, plasma treatment data was from the literature } \\
\text { review and calculation. } \\
\text { Cradle-to-grave (raw material, plasma treatment, end of life) } \\
\text { Waste scenario: } 22.5 \% \text { recycling } \\
\text { PLA < PP < ML < PET (CO } 2 \text { eq.) }\end{array}$ \\
\hline PLA tray vs. PS tray [19] & $\begin{array}{l}\text { Ecoinvent and literature review was used for data as a life cycle inventory. } \\
\text { Cradle-to-grave (tray manufacture, transportation and end of life) } \\
\text { Waste scenario: } 30 \% \text { landfill } \\
\text { PS < PLA ( } \mathrm{CO}_{2} \text { eq.) }\end{array}$ \\
\hline $\begin{array}{l}\text { PLA, PLA/Starch tray vs. PS } \\
\text { tray [21] }\end{array}$ & $\begin{array}{l}\text { Some energy scenarios were conducted for making products and were extracted from } \\
\text { available databases and research works. } \\
\text { Database obtained from Ecoinvent, literature review, and calculation. } \\
\text { Cradle-to-gate (container manufacturer, transportation) } \\
\text { PS < PLA < PLA/starch ( } \mathbf{C O}_{2} \text { eq.) }\end{array}$ \\
\hline $\begin{array}{l}\text { PLA clamshell containers vs. } \\
\text { PET, PS clamshell } \\
\text { containers [8] }\end{array}$ & $\begin{array}{l}\text { Data obtained from Ecoinvent except PLA, which was from literature review. } \\
\text { Cradle-to-grave (container manufacturer, transportation, consumption of the containers, } \\
\text { end of life) } \\
\text { Waste scenario: } 76.5 \% \text { landfill and } 23.5 \% \text { incineration } \\
\text { PS < PLA < PET }\left(\mathbf{C O}_{2} \text { eq.) }\right.\end{array}$ \\
\hline $\begin{array}{l}\text { Wood fiber (W), PLA, TPS (\%) } \\
\text { F1:W(30)/PLA(35)/TPS(35) } \\
\text { F2:W(30)/PLA(70) vs. PP [1] }\end{array}$ & $\begin{array}{l}\text { Production and transport data was obtained from US-EI of changed to national condition } \\
\text { and national database. } \\
\text { Cradle-to-gate (only production) } \\
\text { F1 = F2 }<\text { PP }\left(\mathbf{C O}_{2} \text { eq.) }\right.\end{array}$ \\
\hline
\end{tabular}


Table 1. Cont.

\begin{tabular}{ll}
\hline \multicolumn{1}{c}{ Products } & \multicolumn{1}{c}{ Comments } \\
\hline & Database was sourced from various literature in the review. \\
PHA bag vs. PP bag [20] & $\begin{array}{l}\text { Four kinds of energy scenarios were assessed during the production stage, respectively. } \\
\text { Cradle-to-gate (only production) } \\
\text { PP }<\text { PHA (CO } \mathbf{C O}_{2} \text { eq.) }\end{array}$ \\
\hline & PLA and fossil-based polymer (PVC, PP, HDPE, LDPE, PET, PS, ABS, PC, PMMA, \\
& and polyamide) data was obtained from NatureWorks and PlasticsEurope \\
PLA vs. Fossil based & Cradle-to-pellet \\
polymer [17] & PLA < Fossil based polymer $\left(\mathrm{CO}_{2}\right.$ eq.) \\
\hline
\end{tabular}

\section{Materials and Methods}

In this study, the Publicly Available Specification 2050 [22] was applied to analysis and the principles and guidelines of ISO14040:2006, ISO14044:2006 and ISO14067:2013 were followed [23-25].

\subsection{Goal and Scope}

The goal of this study is to evaluate and compare the carbon footprint of packaging films made from LDPE, PLA, and PLA/PBAT blends using LCA method. The scope of this study is from cradle-to-grave perspective with three waste treatment scenarios based on the present conditions of South Korea.

\subsubsection{Functional Unit}

The functional unit is defined as a film of $300 \times 250 \mathrm{~mm}$ with a thickness of $0.06 \mathrm{~mm}$ for a normal packaging bag. The weight of each film was $4.15 \mathrm{~g}$ (LDPE), $5.58 \mathrm{~g}$ (PLA), and $5.61 \mathrm{~g}$ (PLA/PBAT), calculated by specific gravity. In addition, one production unit of each film was defined as 400,000 pieces for the film manufacturing and transport processes. The characteristics of the three types of packaging films are shown in Table 2. The reference flow is 400,000 pieces of each film.

Table 2. Characteristics of LDPE, PLA, and PLA/PBAT packaging films.

\begin{tabular}{cccccc}
\hline \multirow{2}{*}{ Type } & \multicolumn{3}{c}{ Dimensions } & \multirow{2}{*}{ Weight of Film $\mathbf{( g )}$} & Density (g/cm $\left.{ }^{3}\right)$ \\
\cline { 2 - 4 } & Length $(\mathbf{m m})$ & Width $(\mathbf{m m})$ & Thickness $(\mathbf{m m})$ & & 0.92 \\
LDPE & 300 & 250 & 0.06 & 4.15 & 1.24 \\
PLA & 300 & 250 & 0.06 & 5.58 & 1.25 \\
PLA/PBAT & 300 & 250 & 0.06 & 5.61 & \\
\hline
\end{tabular}

\subsubsection{System Boundary}

The system boundary is described in Figure 1. The cradle-to-gate part of the study was comprised of three stages: raw materials, manufacture, and film extrusion. The cradle-to-grave comprised of five stages among which the stages of usage and disposal were considered. The raw material stage consisted of the manufacturing for a single material. The manufacture stage produced resin for single-layer film. The film extrusion stage contained the process of packaging film manufacturing. The usage part included packaging filling and use, but this stage was excluded from this study. In the disposal stage of this study, three waste treatments were considered: incineration, landfill, and recycling. 


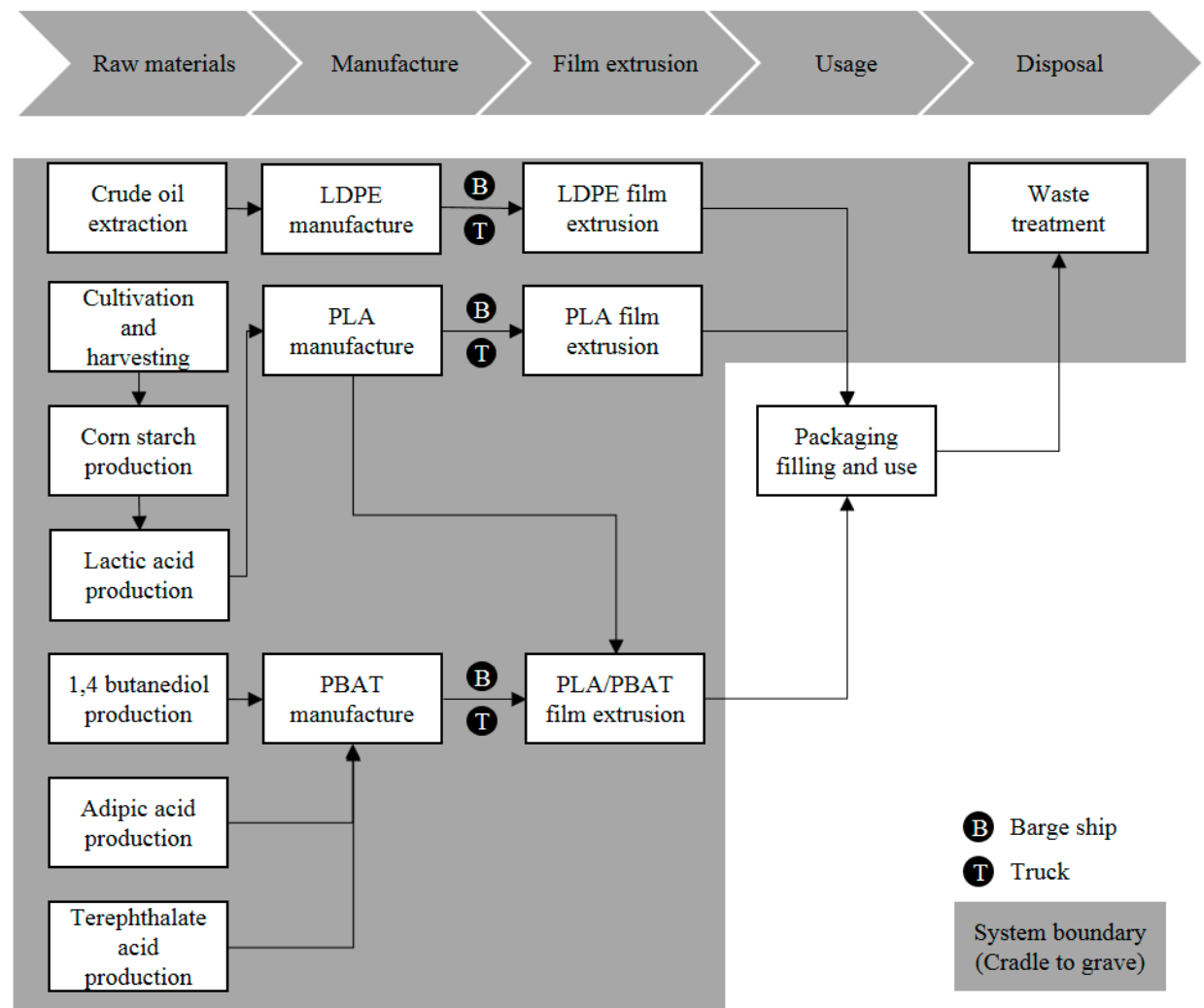

Figure 1. System boundary of this study.

\subsubsection{Assumptions and Limitations}

The assumptions and limitations in this study are as follows:

- Same dimensions of packaging films made from LDPE, PLA, and PLA/PBAT blends have the comparable value for practical use in the packaging sector.

- In the manufacturing process of packaging films, film extrusion was considered only as a primary process.

- A specific temperature for each film in the extrusion process was not considered and was directly proportional to the mass of each film.

- $\quad$ Every database is based on its origin. For example, this study utilized the data of imported LDPE pellets from Europe because the European database of LDPE was applied.

- $\quad$ Packaging filling and use are excluded in this study because of the variety of transport distances and routes travelled by the consumer.

\subsection{Life Cycle Inventory}

\subsubsection{Preparing Packaging Films}

Table 3 show that the sources of inventory data for packaging film production. The PLA production process has five stages: production of corn including transport; extraction of dextrose from corn starch; modification from dextrose to lactic acid; modification from lactic acid to lactide; and PLA pellets production [17]. The life cycle data of PLA is obtained from corn producers of 26 counties in the U.S. The complete stages are calculated based on the Ingeo ecoprofile methodology. The manufacturing of PLA data was collected based on the production of PLA in Nebraska by NatureWorks. The data for LDPE packaging films was collected from the Ecoinvent 3.0 database, available with SimaPro software, and was included in all processes from raw material extraction until delivery at plant. 
Table 3. Sources of inventory data for packaging film production and waste treatment.

\begin{tabular}{ccccc}
\hline Inventory & Source & LDPE & PLA & PLA/PBAT \\
\hline LDPE & Ecoinvent & $\times$ & - & - \\
PLA & Mahalle, L. et al. [17] & - & $\times$ & - \\
PBAT & Modified from Ecoinvent & - & - & $\times$ \\
Extrusion & Modified from Ecoinvent & $\times$ & $\times$ & $\times$ \\
Landfill & KEITI & $\times$ & $\times$ & $\times$ \\
Incineration & KEITI & $\times$ & $\times$ & $\times$ \\
Recycling & KEITI & $\times$ & - & - \\
\hline
\end{tabular}

In the case of PBAT, there was no specific data from an environmental database such as Ecoinvent. According to previous research [26], feedstock requirements for $1 \mathrm{~kg}$ of PBAT were $0.41 \mathrm{~kg}$ of 1,4 butanediol, $0.37 \mathrm{~kg}$ of adipic acid, and $0.33 \mathrm{~kg}$ of terephthalic acid when a synthesis efficiency of $90 \%$ was assumed. Also, its esterification process was comparable to polyethylene terephthalate (PET). Based on these points, the PBAT database was formulated and utilized in the SimaPro software. The PLA/PBAT packaging film applied the ratio of 70\% PLA and 30\% PBAT considering the crystallinity of LDPE and PLA films.

The data of extrusion was collected from the Ecoinvent 3.0. This database was from European and Swiss converting companies and applied from the electricity profile of South Korea. The extrusion database contained auxiliaries and the energy demand for the conversion process of plastic films.

\subsubsection{Transport}

The transport process was considered to be the route from the pellet manufacturing plant to the main port, the route from the main port nearest to the pellet manufacturing plant to the imported country by barge ship, and domestic distribution from port to the film manufacturing factory by truck (see Table 4). The plant of the LDPE and PBAT pellets is assumed to be located in the Netherlands on the basis of the Agri-footprint data profile. The distance from the pellet manufacturing plant to the Rotterdam port was assumed to be $274 \mathrm{~km}$ by a 10 ton truck. The distance from Rotterdam to Busan was assumed to be $21,000 \mathrm{~km}$ by a 320 ton barge ship. The PLA pellet was made in the US. The distance from the pellet manufacturing plant to the LA port was assumed to be $2173 \mathrm{~km}$ by a 10 ton truck. The distance from LA to Busan was assumed to be $9800 \mathrm{~km}$ by a 320 ton barge ship. For domestic distribution, the distance from the Busan port to the film manufacturing factory was assumed to be $327 \mathrm{~km}$ by a 2.5 ton truck. The inventory database of the 10 ton truck and barge ship was collected from Agri-footprint and the 2.5 ton truck transport was based on the Korea Environmental Industry and Technology Institute (KEITI). The government has analyzed the Korean database for LCA since 1995 because of the "Enforcement Decree of the Environmental Technology and Industry Support Act" [27,28].

Table 4. Sources of transport by each packaging film.

\begin{tabular}{cccc}
\hline Packaging Film & Source & Type of Shipment & Distance (km) \\
\hline \multirow{3}{*}{ LDPE } & Agri-footprint & Truck (The Netherlands) & 274 \\
& Agri-footprint & Ocean freighter & 21,000 \\
& KEITI & Truck (South Korea) & 327 \\
\hline \multirow{3}{*}{ PLA } & Agri-footprint & Truck (The US) & 2173 \\
& Agri-footprint & Ocean freighter & 9800 \\
& KEITI & Truck (South Korea) & 327 \\
\hline \multirow{3}{*}{ PLA/PBAT } & Agri-footprint & Truck (The US/ The Netherlands) & $2173 / 274$ \\
& Agri-footprint & Ocean freighter & $9800 / 21,000$ \\
& KEITI & Truck (South Korea) & 327 \\
\hline
\end{tabular}




\subsubsection{Waste Treatments}

Table 3 show that the sources of inventory data for waste treatment. Based on the previous researches [2,29], three waste treatment types (landfill, recycling, and incineration) were considered and utilized as waste treatment scenarios (see Table 5). The bio-plastics such as PLA and PLA/PBAT blends were applied to the incineration (S1) and the landfill (S2), and the recyclable petroleum-based plastic such as LDPE was utilized in all the scenarios. The recycling (S3) was excluded on PLA and PLA/PBAT blends due to bio-based plastics could disturb the current recycling system of existing petroleum-based plastics [30]. All data of waste treatment referred to South Korea national environmental database [27]. Used plastics were recycled to the raw materials of recycled plastic. Recycling process data included specific processes-such as separation, soring, intermediate treatment, melting, and treatment of recycling-for one year. Mixed plastics and LDPE in municipal solid waste (MSW) were incinerated at an incineration facility. Incineration process data included specific processes such as the treatment of burning gas, drain water and incineration ash, input materials, combustion, and the use of the remaining heat during one year. The recovery energy was specified by applying a MSW and heat value ratio. Mixed plastics in municipal solid waste (MSW) were landfilled on reclaimed land. Landfilling process data was a single process and omits the treatment of leachate and land fill gas during the eight years.

Table 5. Waste treatment scenarios.

\begin{tabular}{cc}
\hline Scenarios (S) & Exposition \\
\hline S1 & $100 \%$ incineration \\
S2 & $100 \%$ landfill \\
S3 & $100 \%$ recycling \\
\hline
\end{tabular}

\subsection{Life Cycle Impact Assessment}

A life cycle impact analysis (LCIA) was carried out based on CML-IA baseline v3.03 using SimaPro 8.2.0 software. The CML-IA baseline is a LCA methodology developed by the Center of Environmental Science (CML) of Leiden University in the Netherlands. The CML-IA baseline method elaborates the problem-oriented approach. The CML method support that elevated level of detail allowing to develop a specific environmental picture of each scenario [31]. The GWP was applied and the characterization model, as developed by the Intergovernmental Panel on Climate Change (IPCC), was selected for the development of characterization factors. Factors are expressed as GWP for a time horizon of 100 years (GWP100), in $\mathrm{kg}$ carbon dioxide equivalent $/ \mathrm{kg}$ emission.

\section{Results and Discussion}

\subsection{GWP of Packaging Films}

The GWP results of different packaging films are shown in Figure 2. PLA/PBAT film with incineration (S1) was the worst case of this analysis despite consisting of 70\% PLA. The GWP value of a PLA/PBAT pellet was almost seven times higher compared to a PLA pellet, and over twice higher than a LDPE pellet. PBAT is a petrochemical biodegradable material but the esterification process is similar to that for PET as petroleum-based plastic. [26,32]. In the previous study, PET (amorphous grade) had the highest GWP value among PLA, PVC, PP, HDPE, and LDPE [17]. Therefore, the result of the present study stems from the high GWP value of PET. The PLA with landfill (S2) had the lowest GWP value of approximately three-quarters of LDPE with landfill (S2) and approximately one-half of PLA/PBAT with landfill (S2). Consequently, though PLA was well known for being an environmentally friendly material in terms of GHG emission, blended PLA with other biodegradable materials may have a higher GWP value compared to existing petroleum-based plastics, such as LDPE. 


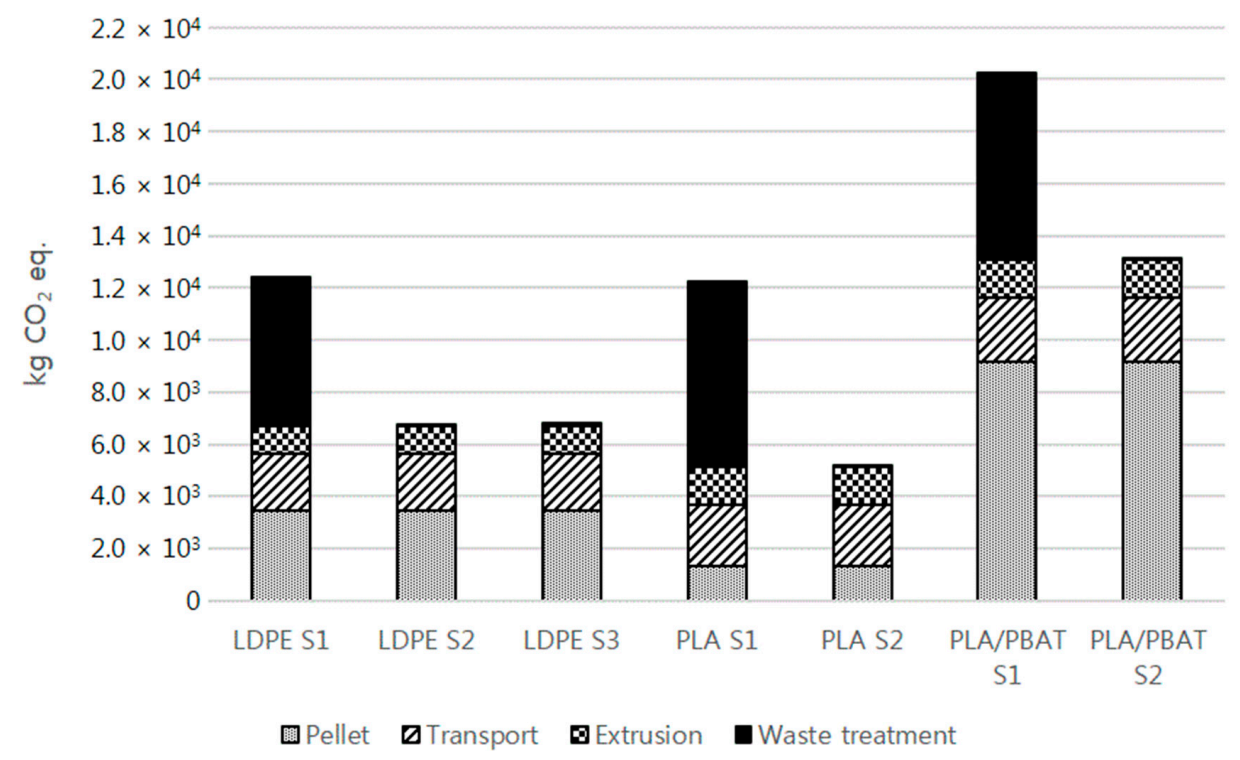

Figure 2. GWP of different packaging films by each waste scenario.

In the pellet stage, the GWP value of PLA/PBAT was highest and next came LDPE and PLA. In the previous study, PBAT/starch blends had lowest carbon dioxide emissions among Bio-PE, $\mathrm{PBAT} /$ starch, and PE [2]. When these results were combined, it seemed that the starch had extremely low carbon dioxide value. In the transport stage, LDPE imported from Europe had the highest GWP value. Next came PLA/PBAT imported from 30\% Europe to 70\% the US. The PLA imported from the US had the lowest GWP value. These results were directly proportional to traffic distance and mode. In the film manufacturing stage, only the extrusion process was considered. The extrusion process was directly proportional to the mass of each material according to specific gravity. LDPE had the lowest GWP value, and next came PLA and PLA/PBAT.

During the waste treatment stage, the incineration of each film had the highest GWP value; next came recycling, and landfill ranked third. In the case of LDPE, the landfill had a GWP value approximately 76 times lower than recycling and 3610 times lower than incineration. The GWP value of PLA and PLA/PBAT with landfill approximately 3280 times higher than incineration. The landfill GWP was calculated by GWP100 of the CML method as an impact assessment, where GWP100 represents GHG emissions for 100 years. Accordingly, the petroleum-based plastic LDPE has a very long degrade period, and the GWP value was lower than recycling. Contrarily, in pursuance of recycling, it was calculated to produce GHG. Although the recycling treatment is more environmentally friendly than landfill, there were limitations to the evaluation due to the conditions of the South Korea database and GWP100 with CML impact assessment method.

Even though the incineration with the energy recovery process was better than without this process in terms of carbon emission [29], carbon dioxide was generated 3280 to 3610 times more than landfill in South Korea. PLA film with landfill treatment was the best case in terms of carbon emissions. In the cases of landfill and incineration, there is no specific data of PLA film in South Korea. Therefore this analysis utilized data of mixed plastics.

\subsection{Relative Contributions of Each Stage}

The relative contributions of each stage are also presented in Figure 3 and Table 6. The largest contribution to the GWP value of the packaging films was from pellet production, excluding the incineration scenario (S1) and this stage of PLA transport. In the case of incineration, this stage of waste treatment constituted more than the other scenarios due to the fact the incineration of MSW is 
the direct factor of GHG emissions [33]. In addition, trucks on the road cause a lot of carbon dioxide emissions [34].

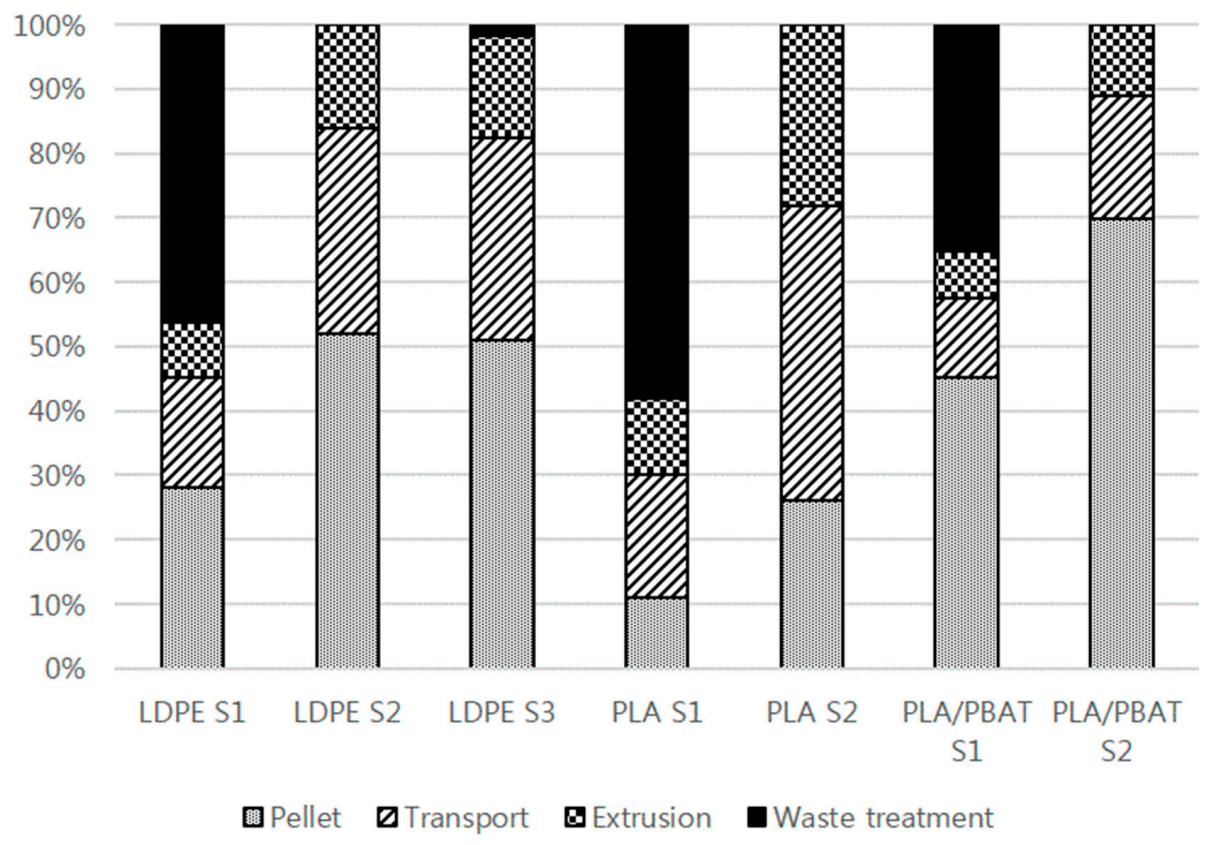

Figure 3. Relative contributions of each stage.

The pellet production ratio of LDPE with the landfill (S2) and the recycling (S3) and PLA/PBAT with the landfill (S2) was over 50 percent. There were several reasons that the carbon dioxide emissions of petroleum-based pallet were more than bio-based plastics. The carbon dioxide emissions of PBAT pellet production is significantly higher than other plastics, therefore, the pellet ratio of PLA/PBAT was the highest among all scenarios. The pellet ratio of the landfill (S2) and the recycling (S3) was relatively higher than the incineration (S1), because the carbon dioxide emissions of landfill and recycling were low.

Even though the PLA was imported from the US to South Korea, a shorter trip than from Europe by barge ship, the GWP value of the PLA transport was higher than the LDPE transport because the distance of the internal transport in the US by truck was eight times longer than that in the Netherlands, and because road transport generates more carbon dioxide emissions than other transportation modes [34].

The carbon dioxide emission ratio of waste treatment was approximately 60 percent in PLA with the incineration (S1). PLA had the highest ratio of waste treatment among all incineration treatment (S1) because, the carbon dioxide emission of the PLA pellet were significantly low. Landfill and recycling had a little carbon dioxide emission ratio. The carbon dioxide emission of waste treatment in the landfill (S2) and the recycling (S3) was significantly lower than the incineration (S1). It was demonstrated that carbon dioxide was directly emitted in the air during burning plastics.

Table 6. Stage contribution results of carbon footprint of packaging films ( $\mathrm{kg} \mathrm{CO}_{2}$ eq.).

\begin{tabular}{cccccccc}
\hline Stage & LDPE S1 & LDPE S2 & LDPE S3 & PLA S1 & PLA S2 & PLA/PBAT S1 & PLA/PBAT S2 \\
\hline Pellet & $3.48 \times 10^{3}$ & $3.48 \times 10^{3}$ & $3.48 \times 10^{3}$ & $1.34 \times 10^{3}$ & $1.34 \times 10^{3}$ & $9.14 \times 10^{3}$ & $9.14 \times 10^{3}$ \\
Transport & $2.15 \times 10^{3}$ & $2.15 \times 10^{3}$ & $2.15 \times 10^{3}$ & $2.35 \times 10^{3}$ & $2.35 \times 10^{3}$ & $2.50 \times 10^{3}$ & $2.50 \times 10^{3}$ \\
Extrusion & $1.07 \times 10^{3}$ & $1.07 \times 10^{3}$ & $1.07 \times 10^{3}$ & $1.44 \times 10^{3}$ & $1.44 \times 10^{3}$ & $1.45 \times 10^{3}$ & $1.45 \times 10^{3}$ \\
Waste treatment & $5.74 \times 10^{3}$ & $1.59 \times 10^{0}$ & $1.21 \times 10^{2}$ & $7.10 \times 10^{3}$ & $2.16 \times 10^{0}$ & $7.14 \times 10^{3}$ & $2.18 \times 10^{0}$ \\
Total & $1.24 \times 10^{4}$ & $6.70 \times 10^{3}$ & $6.82 \times 10^{3}$ & $1.22 \times 10^{4}$ & $5.13 \times 10^{3}$ & $2.02 \times 10^{4}$ & $1.31 \times 10^{4}$ \\
\hline
\end{tabular}




\section{Conclusions}

There have been various studies on the environmental impact of PLA or PLA blends compared with petroleum-based plastics. In previous research, PLA-based plastics had various results in terms of GHG emissions and GWP value than traditional petroleum based plastics regardless cradle-to-grave approach and the waste treatments. Consequently, this study compared the carbon footprint of PLA/PBAT blends film for packaging, which is for improvement of properties with LDPE and PLA films using the LCA method.

Under the present analysis conditions, the PLA film in landfill was the most effective for the GWP among LDPE and PLA/PBAT in every waste scenario. While, PLA/PBAT blending film with incineration had the worst GWP value. Even though PLA was well known for being an environmentally friendly material in terms of GHG emission, blended PLA with other biodegradable materials may have a higher GWP value compared to existing petroleum-based plastic such as LDPE. Consequentially, an environmental evaluation is required prior to the beginning of blending film with a bio-plastic such as PLA. Generally, landfill as a waste treatment may not be the best option in terms of sustainability. However, the landfill of plastic packaging waste was found to be a better option than incineration considering the GWP value in the CML method.

The limitation of this study is that the South Korea national database was applied to the analysis. Therefore, this result may differ from other results using the global or European databases. For future study, there are various biodegradable materials which can blend with PLA. Therefore, various environmental evaluations of material are required for the preparation of PLA blends. In addition, the functional unit may be defined considering the properties of each blend.

Author Contributions: Data curation, B.C. and S.Y.; Formal analysis, B.C. and S.Y.; Methodology, B.C. and S.-i.P.; Project administration, B.C.; Supervision, S.-i.P.; Writing, B.C.; Review and editing, S.-i.P.

Funding: This work was supported by Korea Institute of Planning and Evaluation for Technology in Food, Agriculture, Forestry and Fisheries (IPET) through Export Promotion Technology Development Program, funded by Ministry of Agriculture, Food and Rural Affairs (MAFRA) (117040-3).

Conflicts of Interest: The authors declare no conflicts of interest.

\section{References}

1. Mahalle, L.; Alemdar, A.; Mihai, M.; Legros, N. A cradle-to-gate life cycle assessment of wood fibre-reinforced polylactic acid (PLA) and polylactic acid/thermoplastic starch (PLA/TPS) biocomposites. Int. J. Life Cycle Assess. 2014, 19, 1305-1315. [CrossRef]

2. Saibuatrong, W.; Cheroennet, N.; Suwanmanee, U. Life cycle assessment focusing on the waste management of conventional and bio-based garbage bags. J. Clean. Prod. 2017, 158, 319-334. [CrossRef]

3. Chen, L.; Pelton, R.E.O.; Smith, T.M. Comparative life cycle assessment of fossil and bio-based polyethylene terephthalate (PET) bottles. J. Clean. Prod. 2016, 137, 667-676. [CrossRef]

4. Benetto, E.; Jury, C.; Igos, E.; Carton, J.; Hild, P.; Vergne, C.; Di Martino, J. Using atmospheric plasma to design multilayer film from polylactic acid and thermoplastic starch: A screening life cycle assessment. J. Clean. Prod. 2015, 87, 953-960. [CrossRef]

5. Gupta, A.P.; Kumar, V. New emerging trends in synthetic biodegradable polymers-Polylactide: A critique. Eur. Polym. J. 2007, 43, 4053-4074. [CrossRef]

6. TechNavio. Global Biodegradable Polymers Market 2017-2021; TechNavio: London, UK, 2016.

7. Günkaya, Z.; Banar, M. An environmental comparison of biocomposite film based on orange peel-derived pectin jelly-corn starch and LDPE film: LCA and biodegradability. Int. J. Life Cycle Assess. 2016, 21, 465-475. [CrossRef]

8. Madival, S.; Auras, R.; Singh, S.P.; Narayan, R. Assessment of the environmental profile of PLA, PET and PS clamshell containers using LCA methodology. J. Clean. Prod. 2009, 17, 1183-1194. [CrossRef]

9. Ding, Y.; Lu, B.; Wang, P.; Wang, G.; Ji, J. PLA-PBAT-PLA tri-block copolymers: Effective compatibilizers for promotion of the mechanical and rheological properties of PLA/PBAT blends. Polym. Degrad. Stab. 2018, 147, 41-48. [CrossRef] 
10. Akrami, M.; Ghasemi, I.; Azizi, H.; Karrabi, M.; Seyedabadi, M. A new approach in compatibilization of the poly(lactic acid)/thermoplastic starch (PLA/TPS) blends. Carbohydr. Polym. 2016, 144, 254-262. [CrossRef] [PubMed]

11. Arrieta, M.P.; López, J.; López, D.; Kenny, J.M.; Peponi, L. Biodegradable electrospun bionanocomposite fibers based on plasticized PLA-PHB blends reinforced with cellulose nanocrystals. Ind. Crops Prod. 2016, 93, 290-301. [CrossRef]

12. Srimalanon, P.; Prapagdee, B.; Markpin, T.; Sombatsompop, N. Effects of DCP as a free radical producer and $\mathrm{HPQM}$ as a biocide on the mechanical properties and antibacterial performance of in situ compatibilized PBS/PLA blends. Polym. Test. 2018, 67, 331-341. [CrossRef]

13. Wu, N.; Zhang, H. Mechanical properties and phase morphology of super-tough PLA/PBAT/EMA-GMA multicomponent blends. Mater. Lett. 2017, 192, 17-20. [CrossRef]

14. Narayan, R. Carbon footprint of bioplastics using biocarbon content analysis and life-cycle assessment. MRS Bull. 2011, 36, 716-721. [CrossRef]

15. Ingrao, C.; Tricase, C.; Cholewa-Wójcik, A.; Kawecka, A.; Rana, R.; Siracusa, V. Polylactic acid trays for fresh-food packaging: A Carbon Footprint assessment. Sci. Total Environ. 2015, 537, 385-398. [CrossRef] [PubMed]

16. Poovarodom, N.; Ponnak, C.; Manatphrom, N. Comparative Carbon Footprint of Packaging Systems for Tuna Products. Packag. Technol. Sci. 2012, 25, 249-257. [CrossRef]

17. Vink, E.T.H.H.; Davies, S. Life Cycle Inventory and Impact Assessment Data for 2014 Ingeo ${ }^{\mathrm{TM}}$ Polylactide Production. Ind. Biotechnol. 2015, 11, 167-180. [CrossRef]

18. Vidal, R.; Martínez, P.; Mulet, E.; González, R.; López-Mesa, B.; Fowler, P.; Fang, J.M. Environmental assessment of biodegradable multilayer film derived from carbohydrate polymers. J. Polym. Environ. 2007, 15, 159-168. [CrossRef]

19. Ingrao, C.; Gigli, M.; Siracusa, V. An attributional Life Cycle Assessment application experience to highlight environmental hotspots in the production of foamy polylactic acid trays for fresh-food packaging usage. J. Clean. Prod. 2017, 150, 93-103. [CrossRef]

20. Khoo, H.H.; Tan, R.B.H.; Chng, K.W.L. Environmental impacts of conventional plastic and bio-based carrier bags. Int. J. Life Cycle Assess. 2010, 15, 284-293. [CrossRef]

21. Suwanmanee, U.; Varabuntoonvit, V.; Chaiwutthinan, P.; Tajan, M.; Mungcharoen, T.; Leejarkpai, T. Life cycle assessment of single use thermoform boxes made from polystyrene (PS), polylactic acid, (PLA), and PLA/starch: cradle to consumer gate. Int. J. Life Cycle Assess. 2013, 18, 401-417. [CrossRef]

22. Carbon Trust and Defra. Guide to PAS 2050-How to Assess the Carbon Footprint of Goods and Services, 1st ed.; British Standards Institution: London, UK, 2008; ISBN 978-0-580-64636-2.

23. International Organization for Standardization (ISO). ISO 14040 Environmental Management-Life Cycle Assessment_-Principles and Framework; ISO: Geneva, Switzerland, 2006.

24. International Organization for Standardization (ISO). ISO 14044 Environmental Management-Life Cycle Assessment_-Requirements and Guidelines; ISO: Geneva, Switzerland, 2006.

25. International Organization for Standardization (ISO). ISO ISO/TS 14067 Greenhouse Gases_Carbon Footprint of Products-Requirements and Guidelines for Quantification and Communication; ISO: Geneva, Switzerland, 2013.

26. Schrijvers, D.L.; Leroux, F.; Verney, V.; Patel, M.K. Ex-ante life cycle assessment of polymer nanocomposites using organo-modified layered double hydroxides for potential application in agricultural film. Green Chem. 2014, 16, 4969-4984. [CrossRef]

27. Korea Environmental Industry \& Technology Institute (KEITI). Life Cycle Assessment Software (TOTAL) Manual for eco Labeling [Korean]; KEITI: Seoul, Korea, 2000.

28. Park, J.; Kim, S.; Suh, K. A Comparative Analysis of the Environmental Benefits of Drone-Based Delivery Services in Urban and Rural Areas. Sustainability 2018, 10, 888. [CrossRef]

29. Papong, S.; Malakul, P.; Trungkavashirakun, R.; Wenunun, P.; Chom-in, T.; Nithitanakul, M.; Sarobol, E. Comparative assessment of the environmental profile of PLA and PET drinking water bottles from a life cycle perspective. J. Clean. Prod. 2014, 65, 539-550. [CrossRef]

30. Alaerts, L.; Augustinus, M.; Van Acker, K. Impact of Bio-Based Plastics on Current Recycling of Plastics. Sustainability 2018, 10, 1487. [CrossRef] 
31. Mondello, G.; Salomone, R.; Ioppolo, G.; Saija, G.; Sparacia, S.; Lucchetti, M.C. Comparative LCA of alternative scenarios for waste treatment: The case of food waste production by the mass-retail sector. Sustainability 2017, 9. [CrossRef]

32. Hermann, B.G.; Debeer, L.; De Wilde, B.; Blok, K.; Patel, M.K. To compost or not to compost: Carbon and energy footprints of biodegradable materials' waste treatment. Polym. Degrad. Stab. 2011, 96, 1159-1171. [CrossRef]

33. Lu, Y.T.; Lee, Y.M.; Hong, C.Y. Inventory analysis and social life cycle assessment of greenhouse gas emissions from waste-to-energy incineration in Taiwan. Sustainability 2017, 9. [CrossRef]

34. Choi, B.-L.; Chung, K.-Y.; Lee, K.-D. The impact of policy measures on promoting the modal shift from road to rail. Pers. Ubiquitous Comput. 2014, 18, 1423-1429. [CrossRef]

(c) 2018 by the authors. Licensee MDPI, Basel, Switzerland. This article is an open access article distributed under the terms and conditions of the Creative Commons Attribution (CC BY) license (http:/ / creativecommons.org/licenses/by/4.0/). 